\title{
Os rituais de passagem segundo adolescentes*
}

\author{
Passage rituals according to adolescents \\ Los rituales de pasaje según adolescentes
}

\section{José Roberto da Silva Brêtas ${ }^{1}$, Rafael Souza Moreno ${ }^{2}$, Daniella Soares Eugenio ${ }^{2}$, Danila Cristina Paquier Sala ${ }^{2}$, Thais Fernanda Vieira ${ }^{2}$, Priscila Rabelo Bruno ${ }^{2}$}

\begin{abstract}
RESUMO
Objetivo: Identificar as impressões de adolescentes acerca do que poderia representar um ritual de passagem. Métodos: Estudo descritivo realizado junto a 751 adolescentes de ambos os sexos, entre 12 e 20 anos, que freqüentavam três escolas públicas do ensino fundamental e médio da região de Santo Eduardo do município de Embu, São Paulo. Resultados: Após análise de conteúdo desvelamos as categorias: mudanças físicas; mudanças psicológicas (subcategorias: responsabilidade, experiências, conflitos); mudanças sociais (subcategorias: identidade social, corpo social, inter-relacionamentos); comportamento sexual (subcategorias: interesse sexual, intercurso sexual); fatos traumáticos (subcategorias: sentimento de perda, luto pela infância perdida); independência. Conclusão: Os rituais de passagem relacionam-se diretamente com a mudança corporal, produto do adolescer, sendo ocorrências marcantes e significativas na vida do individuo.
\end{abstract}

Descritores: Adolescente; Comportamento do adolescente; Saúde coletiva

\begin{abstract}
Objective: To identify adolescents' impressions about what could represent a passage ritual. Methods: This descriptive study was performed with 751 adolescents, of both genders, with ages between 12 and 20 years, who attended three public primary and secondary level schools in the Santo Eduardo region in the municipality of Embu, Sao Paulo state. Results: After the content analysis, the following categories were revealed: physical changes; psychological changes (subcategories: responsibility, experiences, conflicts); social changes (subcategories: social identity, social body, interrelationships); sexual behavior (subcategories: sexual interest; sexual intercourse); traumatic factors (subcategories: feeling of lost, mourning for the lost childhood); independence. Conclusion: The passage rituals are directly related to the body changes, a product of adolescence, which are marking and significant occurrences in one's life.
\end{abstract}

Keywords: Adolescent; Adolescent behavior; Colletive health

\section{RESUMEN}

Objetivo: Identificar las impresiones de adolescentes respecto a lo que podría representar un ritual de pasaje. Métodos: Estudio descriptivo realizado con 751 adolescentes de ambos sexos, entre 12 y 20 años, que frecuentaban tres escuelas públicas de enseñanza primaria y secundaria de la región de San Eduardo del municipio de Embu, Sao Paulo. Resultados: Después del análisis de contenido develamos las categorías: cambios físicos; cambios psicológicos (subcategorías: responsabilidad, experiencias, conflictos); cambios sociales (subcategorías: identidad social, cuerpo social, interrelaciones); comportamiento sexual (subcategorías: interés sexual, intercurso sexual); hechos traumáticos (subcategorías: sentimiento de pérdida, duelo por la infancia perdida); independencia. Conclusión: Los rituales de pasaje se relacionan directamente con el cambio corporal, producto del adolecer, siendo ocurrencias que dejan huellas y que son significativas en la vida del individuo.

Descriptores: Adolescente; Conducta del adolescente; Salud colectiva

* O trabalho foi realizado em três ecolas públicas de ensino fundamental e médio da região de Santo Eduardo do município de Embu, (SP), Brasil.

${ }^{1}$ Professor Adjunto da Universidade Federal de São Paulo - UNIFESP, Lider do Grupo de Estudos sobre Corporalidade e Promoção da Saúde GECOPROS - São Paulo (SP), Brasil.

${ }^{2}$ Acadêmicas do Curso de Enfermagem da Universidade Federal de São Paulo - UNIFESP - São Paulo (SP), Brasil. 


\section{INTRODUÇÃO}

Certas etapas do ciclo de vida do ser humano são solenizadas em todas as sociedades por meio de rituais. Chamam-se ritos de passagem as cerimônias que marcam a passagem de um indivíduo ou grupo de uma fase do ciclo para outra.

A vida corresponde a um processo continuo e sucessivo de rituais de passagem, que podem ser verificados: no desmame, no inicio da socialização, ao termino da infância para a adolescência, no inicio do climatério das mulheres e demais passagens vitais que se apresentam intrínsecas na própria natureza humana, que se iniciam desde o nascimento e terminam com a morte. Tais feitos são, na sua maioria, acompanhados de atos especiais que marcam o indivíduo, dando condições de transpor e iniciar uma nova etapa ${ }^{(1)}$.

Os rituais e cerimônias distinguem-se das demais atividades societárias por serem realizados de maneira formal, seguindo padrões estabelecidos pela tradição. Distinguemse, também, por sua natureza simbólica e por se realizarem em ocasiões específicas e períodos determinados.

A partir do contexto apresentado, podemos entender o ritual como um tipo de linguagem, um modo de dizer coisas, na medida em que não só incorpora, mas expressa concepções e valores sociais, religiosos, políticos, econômicos importantes para a sociedade que o pratica.

Utilizando-nos desta perspectiva, destacamos o processo do adolescer como um período de intensas passagens que são vivenciadas pelos jovens durante esse período do seu desenvolvimento.

A adolescência corresponde a um momento de transição entre a infância e a idade adulta, sendo notáveis as mudanças na vida física, social e psicológica. É natural, ao longo desse processo do desenvolvimento biopsicossocial do individuo, ocorrerem situações marcantes que traduzem essa ruptura em novas realidades e percepções sobre a sua existência, consideradas como rituais de passagem da adolescência ${ }^{(2)}$.

$\mathrm{O}$ adolescente vive um período novo em sua vida, buscando, encontrar como definir o seu papel dentro do circulo social no qual está inserido. Nessa nova fase de transição da infância para idade adulta, novas relações interpessoais são vivenciadas e estabelecidas, por meio da interação dentro de um grupo de iguais.

Nesta fase temos a morte da criança para o nascimento do ser adulto ${ }^{(3)}$, abrindo-se uma janela cronológica oportuna para a ocorrência de rituais, que serão elaborados e vivenciados pelos adolescentes, importantes para a construção e consolidação da sua identidade e papel social.

Como ocorrem nos grupos humanos em todas as "passagens", os rituais de iniciação são um elemento interessante na questão da relação entre os jovens e a sociedade, presentes em diferentes formas, em todas as culturas, desde aquelas que chamamos de primitivas até as consideradas modernas ${ }^{(4)}$.

É relevante, neste período de amadurecimento, a busca por uma identidade adulta, que se apresenta estruturada nas primeiras relações afetivas que estes tiveram no âmbito familiar, adequando-as, entretanto, a realidade atual, durante a sua interação com o meio vigente ${ }^{(2)}$.

Os sentimentos adversos advindos das modificações corporais tornam-se comuns entre os adolescentes, os quais experimentam essas passagens evolutivas, possuindo uma mente infantil residente, entretanto em um corpo que vai aproximando-se do estereotipo adulto, levando ao surgimento de alternância de fases que podem ser retratadas como períodos de negação, fuga, revolta, depressão, elaboração, aceitação, timidez, apatia, urgência, conflitos afetivos, crises religiosas e erotismo exarcebado, constituindo um conjunto de acontecimentos denominados de entidade semipatológica ${ }^{(5)}$.

Os rituais de passagem são marcados por cerimônias de separação (preliminares) e de agregação (pósliminares), apresentando na interface desses dois momentos distintos, um período de liminaridade, no qual se estabelece o ritual ${ }^{(6-7)}$. Representa, desta maneira um momento essencial de transformação, transposição e auto-afirmação pelas quais o adolescente vai vivenciar, aquilo que era novo deixara de ser, dando lugar para novas experiências e vivências que contribuíram para seu amadurecimento.

$\mathrm{Na}$ adolescência, com relação ao primeiro período de preparação para o ritual propriamente dito, que corresponde ao período pré-liminar, interligando com processo do adolescer, verifica-se que o adolescente, prepara-se para desenvolver a criação da sua própria identidade, iniciando um período de perdas que são denominados lutos.

É a uma fase de extrema relevância, que deve ser minuciosamente vivida pelos adolescentes. Através dela o indivíduo conseguirá descobrir o seu papel social, adquirindo subsídios como valores, atitudes, crenças, princípios e vontades que serão organizados e assumidos pelo adolescente, servindo de bases para a consolidação do seu processo natural de desenvolvimento psíquico ${ }^{(5)}$.

Os lutos vivenciados pelos adolescentes durante a fase de liminaridade do processo de ritual de passagem para a adolescência podem ser identificados como: luto pela perda do corpo infantil e aceitação das transformações corporais-controle dos impulsos da sexualidade; perda bissexualidade infantil; luto pela perda dos pais da infância; transição da dependência infantil para a independência adulta e busca da identificação fora do âmbito familiar, o que é necessário para o processo de socialização; luto pela perda da identidade e do papel infantil, dificuldade de definir-se como criança ou como adulto, buscando apoio do grupo em que está inserido ${ }^{(5)}$. 
Finalmente, o terceiro momento do ritual denominado pós-liminar, no qual o adolescente retorna a sua normalidade cotidiana, ou seja, momento de transposição, ruptura do período liminar. O individuo deixa de assumir uma identidade transitória e circunstâncias características da fase do luto, para poder adquirir um novo papel social perante a sociedade vigente.

Com base no contexto apresentado e nossa vivência junto em um projeto de extensão universitária desenvolvido com adolescentes, em escolas de ensino fundamental e médio da região de Santo Eduardo, no município de Embu, elaboramos o presente estudo com a finalidade de nortear as atividades desenvolvidas neste projeto. Entendemos a adolescência como um período de transição, com grandes transformações e perdas, em que o ritual de passagem se faz necessário para elaboração dessas mudanças responsáveis pela organização de uma nova identidade. Assim, problematizamos a seguinte questão: Quais acontecimentos representam rituais de passagem, segundo o grupo estudado?

\section{OBJETIVO}

Este estudo teve por objetivo identificar a compreensão da população estudada acerca do que poderia representar um ritual de passagem durante a adolescência.

\section{METODOS}

Trata-se de um estudo descritivo com abordagem qualitativa, no qual utilizamos o método de análise de conteúdo ${ }^{(8)}$.

A análise de conteúdo pode ser definida como um conjunto de técnicas de análise de comunicação visando obter, por procedimentos sistemáticos e objetivos de descrição do conteúdo das mensagens, indicadores que permitem a inferência de conhecimentos relativos às condições de produção/ recepção das mensagens. Neste estudo utilizamos, para análise de conteúdo, a técnica denominada análise categorial que proporcionou o desmembramento do texto em unidades, em categorias segundo reagrupamentos analógicos ${ }^{(8)}$.

O estudo foi desenvolvido no período entre março de 2005 e junho de 2006, com 751 adolescentes de ambos os sexos, sendo 413 garotas (55\%) e 338 rapazes (45\%), com $80 \%$ dos sujeitos estudados entre a faixa etária de 14 e 17 anos (344 garotas e 255 rapazes), que freqüentavam três escolas públicas de ensino fundamental e médio da região de Santo Eduardo do município de Embu. Para obtenção dos dados utilizamos, como recurso, a técnica de entrevista com uma questão norteadora: "A adolescência pode ser considerada a passagem da infância para fase adulta, onde ocorrem muitas mudanças corporais, psicológicas e sociais. Na sua opinião o que poderia representar um ritual de passagem nesta fase de sua vida?". Esta escolha deveu-se ao fato de que a mesma possibilita uma atmosfera de interação e reciprocidade entre quem entrevista e o entrevistado.

A utilização da entrevista não diretiva proporciona a captação de informações que expressam a intercessão do social e do psicológico, em poder capatar, simultaneamente, a ideologia no campo dos processos sociais e no campo dos processos subjetivos individuais. O primeiro campo refere-se a cultura ou a ideologia que remetem as representações e valores de um grupo ou classe social. No segundo campo, dos processos subjetivos, a ideologia é recebida pelos indivíduos por meio de uma série de "identificações introjetadas"; neste caso a ideologia é aprendida na sua relação com o ego como um tipo de ilusão social, na qual se moldam os traços da individualidade. No processo de investigação, o objetivo da entrevista não diretiva consiste em captar as identificações através da fala dos indivíduos, mediante a superação das censuras que nelas se manifestam, o que permitiria a apreensão da ideologia nas suas dimensões social e psicológica ${ }^{(9)}$.

Após a entrevista, foi realizada a análise dos dados com uma leitura integral dos relatos de cada sujeito, para compreender suas percepções. Foram lidos de tal forma a obter-se um sentido geral do todo, de cada relato. Em seguida, uma re-leitura de cada relato, buscando o significado para o adolescente da temática abordada pelo estudo. Assim, os significados foram agrupados por suas semelhanças, dando origem às categorias, a partir da análise das descrições das falas dos sujeitos.

O projeto desta pesquisa foi aprovado pelo Comitê de Ética em Pesquisa da Universidade Federal de São Paulo. Uma vez que obtivemos a aprovação para realização da pesquisa os adolescentes foram orientados e aceitaram participar da mesma, assinando o Termo de Consentimento Livre e Esclarecido. Desta forma, confirmamos que todos os procedimentos metodológicos obedeceram as normas estabelecidas pela Resolução n. ${ }^{\circ}$ 196/96, que trata das Normas de Pesquisa Envolvendo Seres Humanos ${ }^{(10)}$.

\section{RESULTADOS}

Com a estruturação em categorias e subcategorias, buscou-se contornos do sistema de significação que, no seu conjunto revelaram a percepção dos adolescentes entrevistados sobre o tema rituais de passagem. Foram organizadas da seguinte maneira: Categoria Mudanças Físicas; Categoria Mudanças Psicológicas (subcategorias: responsabilidade, experiências, conflitos); Categoria Mudanças Sociais (subcategorias: identidade social, corpo social, inter-relacionamentos); Categoria Comportamento Sexual (subcategorias: interesse sexual, intercurso sexual); Categoria Fatos Traumáticos (subcategorias: sentimento de perda, luto pela infância perdida); 6. Categoria Independência.(Quadro 1) 
Quadro1 - Apresentação das categorias, subcategorias e unidades significativas das percepções de adolescentes em relação ao tema rituais de passagem

\begin{tabular}{|c|c|}
\hline Categorias & Unidades significativas \\
\hline $\begin{array}{l}\text { Mudanças } \\
\text { Físicas }\end{array}$ & $\begin{array}{l}\text { O corpo se alterou bastante e começou a tomar forma de um corpo adulto }(\mathrm{M}) \text {. } \\
\text { Os meninos começam a mudar a voz, nascem pêlos e nas meninas o corpo começa a se desenvolver } \\
(\mathrm{M}) \text {. } \\
\text { Na minha vida de mulher a menstruação, a formação do corpo faz uma adolescente ver que ela já se } \\
\text { tornou mulher (M). } \\
\text { A menarca e a ejaculação, crescimento dos seios, nascimento dos pêlos pubianos, da voz, alargamento } \\
\text { dos quadris, amadurecimento dos ovários podendo então gerar um bebê (M, F). } \\
\text { Foram os meus hormônios (M). } \\
\text { Cresceram várias espinhas no meu rosto }(\mathrm{M}, \mathrm{F}) \text {. }\end{array}$ \\
\hline $\begin{array}{l}\text { Mudanças } \\
\text { Psicológicas }\end{array}$ & $\begin{array}{l}\text { Responsabilidade } \\
\text { Maturidade, responsabilidade e o respeito (F). } \\
\text { Houve mudanças sobre o pensamento em algumas coisas, postura e comportamento (M). } \\
\text { Várias cobranças, mais responsabilidade (M). } \\
\text { Ter mais responsabilidade e lutar pelos meus objetivos (F). } \\
\text { Isso significa muitas coisas para nossas vidas, por exemplo, a liberdade de expressão e a consciência de } \\
\text { saber o que é correto e o errado (M). } \\
\text { Podem representar as mudanças de idéias, sensações e sentimentos (M, F). } \\
\text { Mudanças de opiniões e vontades (M). } \\
\text { Eu comecei a me preocupar com o meu futuro (F). } \\
\text { Experiências } \\
\text { Ritual de passagem para significa experiência, porque a cada dia de sua vida você adquire mais (M, F). } \\
\text { Conhecer e se livrar das drogas (M). } \\
\text { A minha primeira filha (F). } \\
\text { Conflitos } \\
\text { Na adolescência não nos entendemos, mudamos de humor de repente, começam a acontecer coisas } \\
\text { estranhas e, nessa fase geralmente somos chamados de "aborrecentes" (M, F). }\end{array}$ \\
\hline $\begin{array}{l}\text { Mudanças } \\
\text { Sociais }\end{array}$ & $\begin{array}{l}\text { Identidade social } \\
\text { Participar mais na sociedade (M). } \\
\text { Participação política através do meu voto (F). } \\
\text { O mais importante começou a acontecer depois que arrumei meu primeiro emprego (M, F). } \\
\text { Jogar num time e ganhar minha primeira medalha (M). } \\
\text { Corpo social } \\
\text { As preocupações de como me vestir para uma festa, a cor da roupa. Mas [...] é legal ser adolescente (M, } \\
\text { F). } \\
\text { Surge uma maior vaidade [...] a beleza passa a ser prioridade nessa mudança, um imenso de conquistas } \\
\text { e viver (F). } \\
\text { Só penso em andar na moda com roupas novas (M, F). } \\
\text { Inter-relacionamentos } \\
\text { Separação dos meus pais isso me abalou muito e foi um ocorrido que não consigo esquecer (M, F). } \\
\text { O que mudou na minha vida foi o relacionamento com a minha mãe (F). } \\
\text { A partir do meu primeiro beijo. Mudou minha relação com minha mãe, que passou a ser mais aberta. } \\
\text { Minha mãe agora me dá conselhos (F). } \\
\text { Todos os conflitos externos e internos que sofremos nessa fase (F). } \\
\text { Conflitos com os pais por não aceitar ordens (F). } \\
\text { O que ficou marcado foi um amor não correspondido (F). } \\
\text { É uma fase muito significativa, nós sofremos muitas alterações, ficamos rebeldes, mas fazer o que? (M). }\end{array}$ \\
\hline $\begin{array}{l}\text { Comportamento } \\
\text { Sexual }\end{array}$ & $\begin{array}{l}\text { Interesse sexual } \\
\text { Ritual de passagem seria quando deixamos de ser crianças, perdemos o interesse por brinquedos e } \\
\text { passamos a nos interessar pelo outro }(\mathrm{M}, \mathrm{F}) \text {. } \\
\text { Interesse em ter a primeira relação sexual }(\mathrm{M}) \text {. } \\
\text { A minha primeira revista playboy }(\mathrm{M}) \text {. } \\
\text { A gente começa a pensar em ficar e namorar }(\mathrm{F}) \text {. } \\
\text { Quando começamos a sentir desejo de caricias. Começamos a pensar em sexo de uma forma mais } \\
\text { desejável que a normal }(\mathrm{F}) \text {. } \\
\text { Nessa fase a gente começa a se interessar mais pelo sexo oposto }(\mathrm{M}, \mathrm{F}) \text {. } \\
\text { A }(\mathrm{O}) \text { primeira }(\mathrm{o}) \text { namorada }(\mathrm{o})(\mathrm{M}, \mathrm{F}) \text {. } \\
\text { Quando me apaixonei }(\mathrm{F}) \text {. }\end{array}$ \\
\hline
\end{tabular}


...continuação

\begin{tabular}{|c|c|}
\hline & $\begin{array}{l}\text { Intercurso sexual } \\
\text { A melhor coisa que eu achei, foi a primeira vez que eu me masturbei (M). } \\
\text { Foi quando beijei pela primeira vez }(\mathrm{M}, \mathrm{F}) \text {. } \\
\text { Quando comecei a ejacular, ou seja, acordar todo molhado, mas saber que aquilo não era urina e sim } \\
\text { uma coisa totalmente diferente, que era o sêmen, que serve para engravidar uma mulher (M). } \\
\text { A minha vida foi modificada quando eu perdi minha virgindade, eu passei a me sentir a dona do mundo, } \\
\text { tudo mudou em mim, comecei a crescer partes em meu corpo, eu passei a ser mulher esse dia (F). } \\
\text { As primeiras experiências, relações sexuais }(\mathrm{M}, \mathrm{F}) \text {. }\end{array}$ \\
\hline $\begin{array}{l}\text { Fatos } \\
\text { Traumáticos }\end{array}$ & $\begin{array}{l}\text { Sentimento de perda } \\
\text { Foi quando conheci uma pessoa só que não deu tempo para eu conhecer direito. A conheci por dois } \\
\text { anos, ela foi para outro mundo, foi morar com Deus }(\mathrm{M}, \mathrm{F}) \text {. } \\
\text { O destino foi cruel e fez com que minha mãe partisse sem dizer adeus }(\mathrm{M}, \mathrm{F}) \text {. } \\
\text { O dia que marcou a minha vida foi quando os médicos falaram que o meu avô tinha que operar porque a } \\
\text { veia da cabeça dele estourou, este dia foi o pior dia da minha vida (F). } \\
\text { Foi quando a minha mãe operou um tumor no seio que me abalou muito (F). } \\
\text { Luto pela infância perdida } \\
\text { Eu parei de brincar de boneca, de esconde-esconde e de pega-pega (M, F). } \\
\text { Eu cresci, descobri mais do que nunca a saudade da minha boneca (F). } \\
\text { Eu era apenas uma criança de } 14 \text { anos de idade e ainda brincava de boneca e de repente tive que } \\
\text { transformar em mulher e assumir as atividades da casa (F). } \\
\text { A adolescência é uma fase em que você sai do conto de fadas da infância e acorda para o mundo real (F). }\end{array}$ \\
\hline Independência & $\begin{array}{l}\text { Começa sua independência de vida }(\mathrm{M}, \mathrm{F}) \text {. } \\
\text { A mudança mais importante foi que pude tomar minhas decisões }(\mathrm{M}, \mathrm{F}) \text {. } \\
\text { Para mim, o importante foi ter a minha opinião sem a intromissão de ninguém na minha vida pessoal } \\
(\mathrm{M}, \mathrm{F}) \text {. } \\
\text { O que representa a minha passagem de moleque para homem foi poder assistir filmes pornôs e entrar } \\
\text { em casas noturnas }(\mathrm{M}) \text {. } \\
\text { Deixar de morar com os meus pais }(\mathrm{M}) \text {. } \\
\text { É poder fazer coisas que não precisa de autorização }(\mathrm{M}, \mathrm{F}) \text {. } \\
\text { É poder sair com pessoas de sua idade e ir para festas à noite }(\mathrm{M}, \mathrm{F}) \text {. }\end{array}$ \\
\hline
\end{tabular}

\section{DISCUSSÃO}

A categoria "mudanças físicas" foi qualificada de um modo geral como desenvolvimento do corpo e aparecimento de espinhas. Para os meninos a mudança ocorre principalmente, na voz e crescimento de pêlos. Já para as meninas, a mudança tem como marcos iniciais a primeira menstruação, o crescimento dos seios, nascimento de pêlos pubianos e alargamento do quadril, representados nos discursos apresentados no Quadro 1.

Estes acontecimentos, muitas vezes, são considerados embaraçosos para alguns adolescentes, causando sentimentos de vergonha. As novas formas, funções e comportamentos acabam chamando a atenção das pessoas, dentro e fora da família, não apenas para o surgimento de corpo adulto, de homem ou mulher, mas também para a perda da pureza e do corpo infantil. Isso acaba despertando curiosidade e contribuindo para comentários que, nem sempre, agradam o adolescente. A adolescência também traz a sensação de que, com a mudança do corpo, também muda a relação do indivíduo com o mundo que o cerca. Nesse período o adolescente costuma ficar muito retraído e sensível aos estímulos ambientais, principalmente no que tange a sua relação familiar ${ }^{(11)}$.

É importante lembrar que os garotos que participaram do estudo descreveram também mudanças ocorridas no corpo feminino, enquanto as garotas, não descreveram as mudanças no sexo oposto.

A menarca assume papel importante nesta fase de desenvolvimento psicossocial, pois ela continua sendo um marco que identifica a passagem da infância da menina para a adolescência. Muitas vezes, é uma situação valorizada pelas mães e pelas adolescentes.

No senso comum, menstruar é tornar-se "mocinha", ou seja, é adquirir um novo status perante o grupo e a família. É um momento esperado ansiosamente pelas meninas, havendo mesmo certa competição entre elas, criando uma expectativa de quem ficará menstruada primeiro, e quando o fato acontece, é enaltecido para todo o grupo social da adolescente, afinal a menina já é moça. Muitas aguardam este momento ansiosamente, pois está relacionado com o arquétipo feminino da fertilidade (da grande mãe, mãe terra, Gaia) ${ }^{(11)}$.

A chegada da menarca constitui-se em importante elemento definidor da passagem da infância para a adolescência, para todas as adolescentes, independente do seu segmento social, caracterizando-se como um dos poucos ritos de passagem que ainda permanece valorizado nas sociedades modernas.

A categoria "mudanças psicológicas" mostrou um conjunto de acontecimentos emocionais e sociais com origem nas transformações proporcionadas pelo fenômeno da puberdade, que foram encontrados nos relatos dos adolescentes pesquisados, assim desvelando três 
subcategorias, compreendidas como: responsabilidade; experiências; conflitos.

A subcategoria "responsabilidade" tratou de um fator importante de maturidade, no qual o jovem entra em contato, e é constantemente cobrado, nas mais diversas atividades de seu cotidiano, trata-se do passaporte para o mundo adulto ${ }^{(11)}$. Neste sentido, a responsabilização do jovem por suas escolhas e conseqüências é abordada por pais, professores e outros, assim que ele entrar na adolescência. Muitas vezes, as dificuldades e contingências da vida fazem com que o jovem tenha que assumir responsabilidades antes que esteja maduro o suficiente para tal.

A subcategoria "experiências" desvelou a imaturidade do adolescente na sua exposição a certos acontecimentos emergentes da sua relação com o meio, que busca a distinção dos adultos e aquisição de uma nova identidade. $\mathrm{O}$ adolescente elege, às vezes, caminhos distorcidos que são armadilhas sociais, como a drogadição, a prática sexual sem a devida orientação, produzindo a gravidez precoce.

Nas mudanças psicológicas, do ponto de vista feminino, ficou evidenciado o aumento da maturidade, responsabilidade, mudanças de idéias, sensações e sentimentos. Para os meninos, a mudança ocorreu de um modo geral, pois mudam a forma de pensar e a postura. Apenas as meninas relataram a gravidez como experiência, e já os conflitos da adolescência, apareceram em ambos os sexos.

A subcategoria "conflitos" revelou que na adolescência há uma procura do rompimento com a dependência dos pais da infância. Na busca de sua própria identidade adulta, o adolescente trafega por novos grupos sociais e caminhos. A procura por novos valores e padrões de comportamento é um dos canais para a conquista da independência subjetiva, frente aos pais.

$\mathrm{Na}$ prática, conquistar a tão desejada e temida vida adulta significa, para o adolescente, transpor um processo de autoconhecimento, auto-estima e ajuda mútua. Provavelmente, terá maior ou menor facilidade, dependendo dos fatores de proteção com que foi criado e dos riscos e desafios que terá de enfrentar.

Na categoria "mudanças sociais" desvelaram-se três subcategorias, delimitadas por: Identidade Social; Corpo Social; Inter-relacionamentos.

Quanto à subcategoria "Identidade Social", destacamos o interesse pela participação no cotidiano social, o que paulatinamente proporciona a entrada do adolescente no mundo adulto.

Ambos os sexos retrataram prazer nas participações sociais, inclusive o primeiro emprego, sendo uma característica dessa faixa etária, grande interesse e reivindicações pelos assuntos políticos.

$\mathrm{Na}$ subcategoria "corpo social", observamos que o corpo é a tela em que o adolescente vai representar as suas subjetividades, valores criados em nossa sociedade, como a moda, e a inserção em um determinado grupo social.

O aumento da vaidade é perceptível nos dois sexos, sendo com maior freqüência no sexo feminino. Percebemos que a vaidade é uma das "armas" no jogo de sedução entre os sexos.

A subcategoria "inter-relacionamentos" delimitou os conflitos enfrentados pelos adolescentes, que até certo ponto são necessários para a aquisição da identidade adulta.

Nessa subcategoria, percebe-se que existe mudança nos relacionamentos, tendo picos de relacionamento estável, como aconselhamento dos pais e instável, por não aceitar as normas e imposições. Esse comportamento é característico da adolescência, pois o adolescente ao mesmo tempo em que deseja a sua almejada independência, necessita de orientação dos pais. Os conflitos presentes são ocasionados pelas grandes alterações de humores que sofrem nesta fase.

$\mathrm{Na}$ categoria "comportamento sexual" destacaramse duas importantes subcategorias: Interesse Sexual e Intercurso sexual.

A subcategoria "interesse sexual" mostrou a mudança de interesses, em que o adolescente passa a apresentar curiosidades por questões relacionadas a genitalidade, interessando-se pelo outro, do sexo oposto ou não, pelo erotismo e prazer que o novo corpo pode proporcionar.

As mudanças também podem ser determinantes para a erotização do corpo, o surgimento de alguns comportamentos relacionados ao interesse e a prática sexual. Neste período, a pessoa encontra-se sob os domínios da ação dos hormônios sexuais e da genitalidade. O nível de desenvolvimento psicossexual caracterizado pela organização dos impulsos sob o primado das zonas genitais se instituiu a partir da puberdade e adolescência.

Nesta subcategoria observou-se que as meninas relataram, com maior freqüência o inicio do desejo sexual, enquanto os meninos demonstraram interesse pela relação sexual. O surgimento do interesse pelo sexo oposto e primeiro (a) namorado (a) aparecem nos dois sexos.

Pode-se notar que os meninos são mais desinibidos e diretos para tratarem sobre assuntos de sexualidade. Já as meninas, os tratam de forma mais indireta.

A subcategoria "intercurso sexual" desvelou o prazer com as experiências sexuais, consigo mesmo e com o outro, enquanto fatos marcantes na passagem da infância para a fase adulta.

Em relação ao "intercurso sexual", relatos como "ficadas" e namoros, primeiro beijo, enquanto rituais, são comuns aos dois sexos. Alguns acontecimentos fisiológicos e morfológicos ganham maior repercussão entre os adolescentes, como para o sexo masculino às primeiras ejaculações e para o feminino, a virgindade e as suas vicissitudes.

A masturbação aparece apenas como iniciação na prática sexual masculina, demonstrando que esse assunto ainda é 
um tabu social, e abordado ainda de forma velada, entre o grupo feminino. Pode ser considerada como uma prática normal na adolescência, sendo caracterizada como a busca pelo prazer individual e autoconhecimento corporal, além de ser uma manifestação positiva da sexualidade ${ }^{(12)}$.

Outro fato ressaltado pelos depoentes foi a iniciação sexual, que é um forte rito na vida dos indivíduos e de coletividades, pois é normatizada de acordo com parâmetros sobre a juventude, ciclo privilegiado na simbologia de consumo, mitificada por meio da valorização do corpo e da saúde perfeita ${ }^{(13)}$.

A relação sexual é destacada como um rito de passagem, envolvendo distintos trânsitos entre a infância, a adolescência e a juventude. Em tal caminho se dá a afirmação da virilidade, modelagens sobre a feminilidade e a busca por autonomia, o que no senso comum se traduz com o "tornar-se homem" e o "fazer-se mulher", perpassando portanto, sentidos identitários diversos, como o que se entende por masculino e feminino e as realizações das trocas afetivas ${ }^{(14-15)}$.

A adolescência caracteriza-se por diversas transições, sendo a passagem à sexualidade com parceiro(a) a de maior repercussão. O aprendizado da sexualidade, contudo, não se restringe àquele da genitalidade, tampouco ao acontecimento da primeira relação sexual. Trata-se de um processo de experimentação pessoal e de impregnação pela cultura sexual do grupo, que se acelera na adolescência e na juventude. $\mathrm{O}$ aprendizado constituise na familiarização de representações, valores, papéis de gênero, rituais de interação e de práticas, presentes na noção de cultura sexual ${ }^{(16)}$.

A categoria "fatos traumáticos" apresentou duas subcategorias denominadas: "sentimentos de perda" e "luto pela infância perdida".

A subcategoria "sentimentos de perda" revelou a sensação de vazio e impotência que causa a perda de um ente querido, abalando o seu estado de onipotência adolescente.

As perdas aparecem como marco do ritual de passagem em ambos os sexos, mostrando que essa situação, para os adolescentes, estão relacionadas à aquisição de maiores responsabilidades.

Já a subcategoria "luto pela infância perdida" mostrou que a transição é vista pelo (a) adolescente com mais clareza, quando os interesses infantis vão sendo substituídos por interesses mais adultos e, aquilo que até pouco tempo era valorizado como objeto de relação emocional, deixa de ser importante e é abandonado.

Nesta subcategoria encontramos mais relatos femininos e com grande saudosismo da infância. Este fato nos leva a crer que, a mesma possue maiores dificuldades de aceitar o seu "estado" de adolescente, talvez seja pela brusca mudança que ocorre entre as brincadeiras e responsabilidades.
Com relação ao luto pela perda da identidade e do papel infantil, Aberastury e $\mathrm{Knobel}^{(5)}$ relatam que, na dificuldade de definir-se como criança ou como adulto, o adolescente busca apoio do grupo, onde busca novas identificações. Assume diferentes identidades transitórias, ocasionais ou circunstâncias, no sentido de entender sua intimidade e, dessa forma, poder desenhar sua própria identidade.

$\mathrm{Na}$ categoria "independência" identificou-se, principalmente, o movimento do adolescente para afastar-se de sua família, garantindo, assim, a sua própria identidade, fortalecendo-a.

Nesta categoria nota-se que ambos os sexos tomam como marco a independência para tomar decisões, ir a festas e afastar-se da família. Apenas os sujeitos do sexo masculino relataram a independência para poder assistir filmes pornôs. Neste sentido, o aproveitar a vida parece diferenciar o universo do adolescente do mundo adulto.

\section{CONSIDERAÇÕES FINAIS}

É sinal da saúde da sociedade, o fato de que os adolescentes possam ser adolescentes no tempo certo, na idade que abrange o crescimento puberal. Entre os povos primitivos, as mudanças da puberdade ou são escondidas sob tabus ou então o adolescente é convertido num adulto no espaço de algumas semanas ou meses, mediante certos ritos e severas provas de iniciação.

Os ritos da puberdade marcam o momento em que a criança abandona o mundo indiferenciado da infância e passa a ser adolescente, homem ou mulher, pronto para assumir seus papéis no mundo dos adultos. Nas sociedades tribais, os homens passam por rituais que envolvem riscos e, muitas vezes, sofrimentos físicos. São figurações simbólicas de um novo nascimento, da morte da personalidade infantil e substituição pela do homem. Neste sentido, os adolescentes precisam vencer os desafios como forma de poder e capacidade de transição.

Para as mulheres, esses rituais costumam ser mais intimistas e mágicos, como pintar o corpo com determinados produtos da natureza, ouvir cantos sagrados e canções míticas, banhar-se com água com essências. Mas, para ambos os sexos, essas iniciações culturais significam um período educativo (de orientação), os ritos são protetores e têm o propósito de assegurar a felicidade e marcar a passagem para uma nova condição social.

Em nossa cultura, pode-se dizer que já não existem rituais definidos e torna-se difícil delinear, com precisão, essa passagem da infância para a adolescência. Isso quer dizer que o luto, a dor, o turbilhão de emoções e transformações vivenciadas nessa fase já não encontram um apoio social organizado, acolhimento, holding necessário, ou algum ritual simbólico que faça o 
adolescente transcender e compartilhar, coletivamente, a sua passagem para vida adulta. Trata-se de um sujeito cada vez menos coletivo, por outro lado, cada vez mais individual e só. Quer dizer que o adolescente fica entregue a seus próprios conflitos.

\section{REFERÊNCIAS}

1. Abramovitch F, organizador. Ritos de passagem de nossa infância e adolescência: antologia. São Paulo: Summus Editorial; 1985.

2. Brêtas JRS. A mudança corporal na adolescência: a grande metamorfose. Temas Desenvolv. 2004; 12(72): 29-38.

3. Silva ALP, Soares DHP. A orientação profissional como rito preliminar de passagem: sua importância clínica. Psicol Estud. 2001; 6(2): 115-21.

4. Outeiral J. Adolescer: estudos revisados sobre adolescência. 2a ed. Rio de Janeiro: Revinter; 2003.

5. Aberastury A, Knobel M. Adolescência normal. Porto Alegre: Artes Médicas; 1981.

6. Turner VW. O processo ritual: estrutura e antiestrutura. Petrópolis: Editora Vozes; 1974.

7. Van Gennep A. Os ritos de passagem: estudo sistemático dos ritos da porta e da soleira, da hospitalidade, da adoção, gravidez e parto, nascimento, infância, puberdade, iniciação, ordenação, coroação, noivado, casamento, funerais, estações, etc. Petrópolis: Editora Vozes; 1978.

8. Bardin L. Análise de conteúdo. Lisboa: Edições 70; 1995.

9. Thiollent M. Crítica metodológica, investigação social e enquete operária. 5a. ed. São Paulo: Polis; 1987.
Neste contexto, procuramos entender e valorizar tais dados, utilizando-os na elaboração do conteúdo das oficinas de orientação sexual do Projeto de Extensão "Corporalidade e Promoção da Saúde", desenvolvidas nas escolas mencionadas.

10. Brasil. Ministério da Saúde. Conselho Nacional de Saúde. Resolução n.196 de 10 de outubro de 1996. Diretrizes e normas regulamentadoras de pesquisas em seres humanos. Mundo Saúde. 1996; 21(1): 52-61.

11. Brêtas JRS. Mudanças: a corporalidade na adolescência [tese doutorado]. São Paulo: Universidade Federal de São Paulo. Escola Paulista de Medicina; 2003.

12. Domingues CMAS, Alvarenga AT. Identidade e sexualidade no discurso adolescente. Rev Bras Crescimento Desenvolv Hum. 1997; 7(2): 32-68.

13. Vianna LCR. A idade mídia: uma reflexão sobre o mito da juventude na cultura de massa. Brasília: UnB; 1992.

14. Galland O. Sociologie de la jeunesse. Paris: Armand Colin; 1997.

15. Nolasco S. O mito da masculinidade. Rio de Janeiro: Rocco; 1993.

16. Heilborn ML. Experiência da sexualidade, reprodução e trajetórias biográficas juvenis. In: Heilborn ML, Aquino EML, Bozon M, Knauth DR, organizadores. Aprendizado da sexualidade: reprodução e trajetórias sociais de jovens brasileiros. Rio de Janeiro: Garamond: Fiocruz; 2006. p.2959. 